\title{
Peramalan Perencanaan Produksi Batu Tela Dengan Metode Exponential Smoothing (Studi Kasus Pada CV. Sinar Sowi Kabupaten Manokwari)
}

\author{
Suwoko $^{1}$, Dirarini Sudarwadi ${ }^{2}$, Nurwidianto ${ }^{3}$ \\ ${ }^{1}$ Alumni Jurusan Manajemen, Universitas Papua \\ ${ }^{2,3}$ Dosen Jurusan Manajemen, Universitas Papua
}

Received: Mei 2019; Accepted: Agustus 2019; Published: September 2019

\begin{abstract}
Abstrak
Penelitian ini bertujuan untuk mengetahui seberapa besar peramalan jumlah produksi batu tela pada CV. Sinar Sowi. Metode analisis data yang digunakan adalah metode Exponential Smoothing dengan menggunakan pengukuran kesalahan peramalan yaitu Mean Square Error (MSE) dan Mean Absolute Deviation (MAD). Dari data yang telah dianalisis, penulis dapat mengambil kesimpulan bahwa penggunaan model alpha 0,1 metode Exponential Smoothing, nilai metode Exponential Smoothing, nilai Mean Square Error adalah 11.114.950 dan nilai Mean Absolute Deviation adalah 962. Penggunaan model alpha 0.5 metode Exponential Smoothing, nilai Mean Square Error adalah 1.114.776 dan nilai Mean Absolute Deviation adalah 305. Sementara penggunaan model alpha 0.9 metode Exponential Smoothing, nilai Mean Square Error adalah -9.374 dan nilai Mean Absolute Deviation adalah -28. Dari ketiga model alpha yang ada yaitu 0.1;0.5 dan 0.9, maka yang akan digunakan dalam peramalan adalah alpha 0.9 karena nilai errornya merupakan yang terendah yaitu Mean Square Error sebesar 9.374 dan Mean Absolute Deviation adalah -28. Dari perhitungan peramalan batu tela pada CV. Sinar Sowi Kabupaten Manokwari maka didapat hasil peramalan sebesar 39.698 unit.
\end{abstract}

Kata kunci: rencana produksi, metode peramalan

\begin{abstract}
This study aims to find out how much forecasting the production of concrete brick at CV. Sinar Sowi. The data analysis method used is the Exponential Smoothing method by using forecasting error measurements namely Mean Square Error (MSE) and Mean Absolute Deviation (MAD). From the data that has been analyzed, the writer can conclude that the use of alpha model 0.1 Exponential Smoothing method, the value of the Exponential Smoothing method, the value of Mean Square Error is 11,114,950 and the value of Mean Absolute Deviation is 962. The use of alpha 0.5 model Exponential Smoothing method, the value of Mean Square Error is 1,114,776 and the value of Mean Absolute Deviation is 305. While the use of the alpha 0.9 model is Exponential Smoothing, the Mean Square Error value is -9.374 and the Mean Absolute Deviation value is -28. Of the three existing alpha models, namely 0.1; 0.5 and 0.9, then what will be used in forecasting is alpha 0.9 because the error value is the lowest, namely the Mean Square Error of -9,374 and Mean Absolute Deviation is -28. From the calculation of concrete brick forecasting at CV. Sinar Sowi in Manokwari Regency, the forecasting results were 39,698 units.
\end{abstract}

Keywords: production planning, forecasting method

How to Cite: Suwoko, Sudarwadi, D., Nurwidianto (2019). Peramalan Perencanaan Produksi Batu Tela Dengan Metode Exponential Smoothing (Studi Kasus Pada CV. Sinar Sowi Kabupaten Manokwari). JFRES: Journal of Fiscal and Regional Economy Studies, 2 (2), 54 - 59. 


\section{PENDAHULUAN}

Kegiatan ekonomi adalah kegiatan seseorang atau sekumpulan orang (perusahaan) untuk memproduksi barang dan/atau jasa maupun mengkonsumsi (menggunakan) barang dan/atau jasa tersebut. Umumnya kegiatan ekonomi terdiri dari kegiatan konsumsi, produksi dan distribusi. Barang dan jasa yang dihasilkan dari kegiatan produksi, nantinya akan didistribusikan untuk bisa menjangkau konsumen, agar konsumen dapat memenuhi kebutuhannya.

Perkembangan dan pertumbuhan ekonomi pada era globalisasi ini, berkembang dengan sangat cepat. Hal itu menuntut bangsa kita untuk terus meningkatkan pembangunan di segala bidang. Perkembangan ekonomi tersebut menuntut kesiapan semua pelaku ekonomi agar selalu dapat beradaptasi dengan perubahan yang mungkin terjadi. Hal ini dikarenakan perkembangan ekonomi menyebabkan persaingan yang tajam diantara badan-badan usaha yang ada (Mayasari dkk, 2008 dalam Bukorpioper, 2018).

Untuk mengatasi persaingan yang tajam diantara para pelaku bisnis tersebut diperlukan kebijakan-kebijakan yang dapat menguntungkan perusahaan. Sumayang (2003) menyatakan bahwa "Perubahan kondisi ekonomi mendorong manajer untuk mengubah peramalan atau proyeksi permintaan pasar dan akan mengambil keputusan pengembangan atau pengurangan kapasitas".

Salah satu keputusan penting dalam perusahaan yang dilakukan oleh manajemen adalah menentukan tingkat produksi dari barang atau jasa yang perlu disiapkan untuk masa datang. Penentuan tingkat produksi, yang merupakan tingkat penawaran, dipengaruhi oleh jumlah permintaan pasar yang dapat dipenuhi oleh perusahaan. Tingkat penawaran yang lebih tinggi dari permintaan pasar dapat mengakibatkan terjadinya pemborosan biaya, seperti biaya penyimpanan, biaya modal, dan biaya kerusakan barang. Tingkat penawaran yang lebih rendah dibandingkan kemampuan pangsa pasar yang dapat diraih mengakibatkan hilangnya kesempatan untuk memperoleh keuntungan, bahkan mengakibatkan hilangnya pelanggan karena beralih ke pesaing (Herjanto, 2008). Perusahaan harus bisa memastikan ketersediaan produk tidak akan mengalami shortage. Terjadinya shortage akan berimplikasi pada hilangnya kesempatan untuk melakukan penjualan produk. Penentuan jumlah produk yang akan diproduksi menjadi hal yang paling penting atau bahkan dapat dikatakan menjadi kunci utama dalam perencanaan produksi yang tepat, sehingga pada akhirnya perusahaan tidak akan mengalami shortage (kekurangan produksi) atau terjadi kelebihan produksi.

Untuk mengatasi hal diatas maka diperlukan sebuah rencana atau rancangan terkait dengan perencanaan produksi ke depan. Sumayang (2003) dalam bukunya yang berjudul Dasardasar Manajemen Produksi \& Operasi menyatakan "peramalan penting artinya karena dengan peramalan yang tepat-guna diharapkan akan meningkatkan efisiensi produksi”.

Dalam hal perencanaan produksi, aktivitas peramalan atau forecasting merupakan kegiatan untuk memperikirakan jumlah produk yang akan diproduksi sehingga akan didapatkan hasil dari kuantitas produk yang akan diproduksi dengan tepat. Hasil dari aktivitas perencanaan produksi adalah menetapkan produk yang diproduksi serta jumlah yang dibutuhkan.

"Forecasting (peramalan) adalah salah satu unsur yang sangat penting dalam pengambilan keputusan. Suatu dalil yang dapat diterima bahwa semakin baik ramalan tersedia untuk pimpinan, semakin baik pula prestasi kerja mereka sehubungan dengan keputusan yang diambil" (Sidik, 2010). Berdasar hal tersebut peramalan atau perencanaan produksi sangat penting bagi sebuah perusahaan agar dapat mengambil sebuah keputusan yang baik.

Perencanaan atau rancang bangun sebagai salah satu fungsi pengambilan keputusan manajemen produksi dan operasi, membutuhkan sebuah ramalan tentang permintaan yang biasa disebut "demand" terhadap produk barang dan jasa yang dihasilkan oleh sistem produksi ini. Kebutuhan akan jawaban tentang perubahan pasar yang cepat akan memerlukan peramalan yang tepat. Peramalan produksi menjadi penting karena untuk menentukan jumlah unit barang yang harus diproduksi agar tidak terjadi kelebihan atau kekurangan persediaan barang produksi.

Dalam aktivitas perusahaannya, CV. Sinar Sowi memproduksi keperluan bangunan, seperti meubelair dan batu tela. Batu tela 
merupakan produk yang mendominasi dibandingkan produk lain dalam aktivitas produksi CV. Sinar Sowi. Hal ini disebabkan oleh lebih banyaknya permintaan produk batu tela dibanding produk lain, dalam hal ini perusahaan juga menerapkan peramalan dalam target permintaan, namun peramalan yang dilakukan oleh perusahaan belum akurat, karena hasil peramalan yang didapat belum mendekati dengan kenyataan hasil yang didapat, hal ini dikarenakan perusahaan belum menggunakan metode-metode peramalan yang akurat, perusahaan dalam peramalannya hanya memperkirakan saja tanpa menggunakan ilmu pasti. Oleh sebab itu akan muncul permasalahan untuk meramalkan jumlah permintaan pada periode berikutnya dengan penerapan metode-metode peramalan, agar hasil yang didapatkan lebih akurat.

Berdasarkan latar belakang diatas, maka tujuan penelitian ini adalah untuk mengestimasi berapa besar jumlah produksi batu tela $\mathrm{CV}$. Sinar Sowi.

Dalam penelitian ini, metode Exponential Smoothing digunakan untuk meramalkan volume produksi batu tela pada CV. Sinar Sowi Kabupaten Manokwari berdasarkan datadata terdahulu yang diperoleh dari pihak perusahaan. Data yang digunakan adalah data produksi atau data penjualan selama tahun 2018.

\section{METODE PENELITIAN}

\section{Data}

Data penelitian ini berupa data kuantitatif dan data kualitatif. Data bersumber dari data primer dan data sekunder. Metode pengumpulan data meliputi observasi, dokumentasi dan wawancara

\section{Metode Analisis}

Analisis data yang digunakan dalam penelitian ini adalah metode exponential smoothing. Handoko (2016) menjelaskan "Exponential Smoothing adalah suatu tipe teknik peramalan rata-rata bergerak yang melakukan penimbangan terhadap data masa lalu dengan cara eksponensial sehingga data paling akhir mempunyai bobot atau timbangan lebih besar dalam rata-rata bergerak. Dengan exponential smoothing sederhana, forecast dilakukan dengan cara ramalan periode terakhir ditambah porsi perbedaan (disebut $\alpha$ ) antara permintaan nyata periode terakhir dan ramalan periode terakhir. Nilai $\alpha$ yang menghasilkan tingkat kesalahannya yang paling kecil adalah yang dipilih dalam peramalan (Arsyad, 1997).

Persamaan ramalan exponential smoothing ini adalah:

$$
\mathrm{F}_{\mathrm{t}}=\mathrm{F}_{\mathrm{t}-1}+\alpha\left(\mathrm{A}_{\mathrm{t}-1}-\mathrm{F}_{\mathrm{t}-1}\right)
$$

Dengan keterangan sebagai berikut:

$\mathrm{F}_{\mathrm{t}}=$ ramalan untuk periode sekarang $(\mathrm{t})$

$\mathrm{F}_{\mathrm{t}-1}=$ ramalan yang dibuat untuk periode terakhir (t-1)

$\alpha=$ smoothing constant $(0<\alpha<1)$

$\mathrm{A}_{\mathrm{t}-1}=$ permintaan nyata periode terakhir

Menurut Render dan Heizer (2001) permasalahan umum yang dihadapi dalam metode ini adalah bagaimana memilih $\alpha$ yang tepat untuk meminimumkan kesalahan peramalan. Karena berlaku $0<\alpha<1$ maka dapat menggunakan panduan berikut:

a. Apabila pola historis dari data aktual sangat bergejolak atau tidak stabil dari waktu ke waktu maka pilih nilai $\alpha$ yang mendekati satu

b. Apabila pola historis dari data aktual permintaan tidak berfluktuasi atau relatif stabil maka pilih nilai $\alpha$ yang mendekati nol.

\section{Pengukuran Akurasi Peramalan}

Untuk menghitung kesalahan hasil ramalan biasa digunakan mean square error dan mean absolute deviation

1. Mean square error (MSE) atau rata-rata kesalahan ramalan

MSE merupakan metode alternatif dalam suatu metode peramalan. Pendekatan ini penting karena teknik ini menghasilkan kesalahan yang moderat lebih disukai oleh suatu peramalan menghasilkan kesalahan yang sangat besar. MSE dihitung dengan menjumlahkan kuadrat semua kesalahan peramalan pada setiap periode dan membaginya dengan jumlah periode peramalan. Secara matematis MSE dirumuskan sebagai berikut (Nasution dan Prasetyawan, 2008):

$$
M A D=\frac{\sum\left|X_{t}-F_{t}\right|^{2}}{n}
$$


Dimana:

$\mathrm{Xt}=$ Permintaan aktual pada periode $-\mathrm{t}$

$\mathrm{Ft}=$ Peramalan permintaan (forecast) pada periode $-\mathrm{t}$

$\mathrm{n}=$ jumlah periode peramalan yang terlibat

2. Mean Absolute Deviation (MAD) atau ratarata deviasi mutlak

MAD merupakan rata-rata kesalahan mutlak selama periode tertentu tanpa memperhatikan apakah hasil peramalan lebih besar atau lebih kecil dibandingkan kenyataannya. Secara matematis, MAD dirumuskan sebagai berikut (Nasution dan Prasetyawan, 2008).

$$
M A D=\frac{\sum\left|X_{t}-F_{t}\right|}{n}
$$

Dimana:

$\mathrm{Xt}=$ Permintaan aktual pada periode $-\mathrm{t}$

$\mathrm{Ft}=$ Peramalan permintaan $($ forecast $)$ pada periode $-t$

$\mathrm{n}=$ jumlah periode peramalan yang terlibat

\section{HASIL DAN PEMBAHASAN}

Untuk dapat melakukan peramalan diperlukan data-data dari periode sebelumnya. Data periode sebelumnya digunakan sebagai panduan untuk dapat melakukan peramalan. Adapun data yang digunakan yaitu data penjualan batu tela CV. Sinar Sowi selama kurun waktu 12 bulan.
Tabel 1. Penjualan Batu Tela Tahun 2018

\begin{tabular}{ccc}
\hline No. & Bulan & Penjualan (unit) \\
\hline 1 & Januari & 40.000 \\
2 & Februari & 44.250 \\
3 & Maret & 51.000 \\
4 & April & 44.250 \\
5 & Mei & 44.250 \\
6 & Juni & 29.250 \\
7 & Juli & 35.000 \\
8 & Agustus & 36.500 \\
9 & September & 45.000 \\
10 & Oktober & 46.000 \\
11 & November & 46.000 \\
12 & Desember & 39.000 \\
\hline
\end{tabular}

Sumber: Data primer, 2018

\section{Analisis Data Menggunakan Metode Exponential Smoothing}

Sebelum melakukan analisis menggunakan metode exponential smoothing terlebih dahulu kita mencari nilai alpha yang akan digunakan dalam pemodelan. Untuk itu dilakukan trial and error menggunakan exponential smoothing terhadap data aktual yang ada.

Percobaan yang akan dilakukan adalah dengan menggunakan 3 (tiga) nilai alpha yaitu: 0.1, 0.5 dan 0.9 karena diambil dari nilai alpha yang paling rendah, sedang hingga nilai alpha yang tertinggi.

Tabel 2. Penjualan Aktual dan Forecast Batu Tela Tahun 2018

\begin{tabular}{ccccc}
\hline Bulan & Actual & \multicolumn{3}{c}{ Forecast (Exponential Smoothing) } \\
\hline & & 0.1 & 0.5 & 0.9 \\
Januari & 40.000 & 40.000 & 40.000 & 40.000 \\
Februari & 44.250 & 40.000 & 40.000 & 40.000 \\
Maret & 51.000 & 40.425 & 42.125 & 43.825 \\
April & 44.250 & 41.482 & 46.562 & 50.282 \\
Mei & 44.250 & 41.759 & 45.406 & 44.853 \\
Juni & 29.250 & 42.008 & 44.828 & 44.310 \\
Juli & 35.000 & 40.732 & 37.039 & 30.756 \\
Agustus & 36.500 & 40.159 & 36.020 & 34.576 \\
September & 45.000 & 39.793 & 36.260 & 36.308 \\
Oktober & 46.000 & 40.314 & 40.630 & 44.131 \\
November & 46.000 & 40.883 & 43.315 & 45.813 \\
Desember & 39.000 & 41.394 & 44.567 & 45.981 \\
\hline
\end{tabular}

Sumber: Data diolah, 2019

Hasil perhitungan Mean Square Error (MSE) dan Mean Absolute Deviation (MAD) disajikan pada Tabel 3. Dilihat dari tabel pengukuran akurasi peramalan, maka nilai error terkecil adalah nilai alpha 0.9 yang selanjutnya nilai alpha tersebut yang akan digunakan dalam melakukan peramalan batu tela CV. Sinar Sowi untuk periode ke depan.
Dalam penentuan alpha untuk pemodelan exponential smoothing, dipilih nilai alpha yang memiliki tingkat kesalahan yang terkecil karena untuk meminimalkan kesalahan ramalan. Berikut adalah hasil peramalan batu tela CV. Sinar Sowi menggunakan metode Exponential Smoothing. 
Tabel 3. Parameter Pengukuran Kesalahan Peramalan

\begin{tabular}{|c|c|c|c|}
\hline & 0,1 & 0.5 & 0.9 \\
\hline MAD & 962 & 305 & -28 \\
\hline MSE & 11.114 .950 & 1.114 .776 & -9.374 \\
\hline
\end{tabular}

\section{Sumber: Data diolah, 2019}

Tabel 4. Hasil forecasting Batu Tela CV. Sinar Sowi

\begin{tabular}{cccc}
\hline No. & Bulan & Actual & Forecast \\
\hline 1 & Januari & 40.000 & 40.000 \\
2 & Februari & 44.250 & 40.000 \\
3 & Maret & 51.000 & 43.825 \\
4 & April & 44.250 & 50.282 \\
5 & Mei & 44.250 & 44.853 \\
6 & Juni & 29.250 & 44.310 \\
7 & Juli & 35.000 & 30.756 \\
8 & Agustus & 36.500 & 34.576 \\
9 & September & 45.000 & 36.308 \\
10 & Oktober & 46.000 & 44.131 \\
11 & November & 46.000 & 45.813 \\
12 & Desember & 39.000 & 45.981 \\
13 & Januari & & 39.698 \\
\hline
\end{tabular}

\section{Sumber: Data diolah, 2019}

Dari perhitungan peramalan batu tela menggunakan metode Exponential Smoothing diperoleh hasil ramalan untuk periode kedepan yaitu sebesar 39.698 unit batu tela dengan nilai

Tabel 5 Hasil forecasting

\begin{tabular}{cccc}
\hline No. & Bulan & Actual & Forecast \\
\hline 1 & Januari & 40.000 & 40.000 \\
2 & Februari & 44.250 & 40.000 \\
3 & Maret & 51.000 & 43.825 \\
4 & April & 44.250 & 50.282 \\
5 & Mei & 44.250 & 44.853 \\
6 & Juni & 29.250 & 44.310 \\
7 & Juli & 35.000 & 30.756 \\
8 & Agustus & 36.500 & 34.576 \\
9 & September & 45.000 & 36.308 \\
10 & Oktober & 46.000 & 44.131 \\
11 & November & 46.000 & 45.813 \\
12 & Desember & 39.000 & 45.981 \\
13 & Januari & & 39.698 \\
& & & \\
& MSE & -28 & \\
\hline
\end{tabular}

Sumber: Data diolah, 2019

\section{KESIMPULAN DAN SARAN}

Dari hasil penelitian ini, maka dapat dibuat kesimpulan sebagai berikut. Berdasarkan penggunaan model alpha 0.1 metode Exponential Smoothing, nilai Mean Square Error adalah 11.114.950 dan nilai Mean Absolute Deviation adalah 962. Penggunaan model alpha 0.5 metode Exponential Smoothing, nilai Mean Square Error adalah 1.114.776 dan nilai Mean Absolute Deviation adalah 305. Sementara penggunaan model
MSE sebesar -9.374 dan nilai MAD sebesar 28. Hal ini menunjukkan aka ada kenaikan tingkat produksi batu tela dari bulan sebelumnya ke bulan berikutnya. alpha 0.9 metode Exponential Smoothing, nilai Mean Square Error adalah -9.374 dan nilai Mean Absolute Deviation adalah -28. Dari ketiga model alpha yang ada yaitu $0.1 ; 0.5$ dan 0.9, maka yang akan digunakan dalam peramalan adalah alpha 0.9 karena nilai errornya merupakan yang terendah yaitu Mean Square Error sebesar -9.374 dan Mean Absolute Deviation adalah -28. Dari perhitungan peramalan Batu Tela pada CV. Sinar Sowi Kabupaten Manokwari maka didapat hasil peramalan sebesar 39.698 unit. 
Berdasarkan hasil analisis, maka dapat dikemukakan saran-saran sebagai berikut. Bagi perusahaan, sebaiknya menerapkan metode Exponential Smoothing dengan alpha 0.9 dalam melakukan peramalan permintaan karena hasil pengujian menunjukkan nilai error yang terkecil. Bagi peneliti selanjutnya yang memiliki topik penelitian yang sama dapat menggunakan metode yang berbeda dalam proses forecasting produksi seperti metode ARIMA Box Jenkins, Mix Integer Programming dan lainnya.

\section{DAFTAR PUSTAKA}

Agung, Akbar. 2009. Penerapan Metode Single Moving Average dan Exponential Smoothing dalam Peramalan Permintaan Produk Meubel Jenis Coffe Table pada Java Furniture Klaten. Skripsi. Fakultas Ekonomi, Universitas Sebelas Maret, Surakarta

Arsyad, Lincolin. 1997. Peramalan Bisnis. Edisi Pertama BPFE. Yogyakarta

Bukorpioper, Michael. 2018. Pengaruh Hutang Jangka Pendek dan Hutang Jangka Panjang terhadap Tingkat Profitabilitas (Studi Kasus Perusahaan yang Masuk dalam Indeks LQ45 yang Terdaftar di Bursa Efek Indonesia Periode 2012-2016). Skripsi. Jurusan Manajemen, Fakultas Ekonomi dan Bisnis, Universitas Papua, Manokwari.

Dharmesta, Adri dkk. 2015. Peramalan Perencanaan Produksi Terak dengan Metode Exponential Smoothing with Trend pada PT. Semen Indonesia (PERSERO) Tbk. Jurnal. Program Studi Teknik Industri, Fakultas Teknik, Universitas Diponegoro, Semarang

Deitiana, T., MM. 2011. Manajemen Operasional Strategi dan Analisa. Jakarta. Mitra Wacana Media

Fred R. David. 2011. Strategic Management Manajemen Strategis Konsep. Jakarta. Salemba Empat

H. A. Rusdiana M.M. 2014. Manajemen Operasi. Bandung: Pustaka Setia

Haming, Murdifin dan Mahfud Nurnajamuddin. 2014. Manajemen Produksi Modern; Operasi Manufaktur dan Jasa. Jakarta. PT. Bumi Aksara
Herjanto, Edy. 2008. Manajemen Operasi Edisi Ketiga. Jakarta. Grasindo

Juliandi, Azuar dkk.. 2014. Metodologi Penelitian Bisnis. Medan. UMSU Press

Nasution, Arman Hakim dan Yudha Prasetyawan. 2008. Perencanaan dan Pengendalian Produksi. Yogyakarta. Graha Ilmu

Render dan Heizer. 2001. Prinsip- Prinsip Manajemen Operasi. Jakarta. Salemba Empat.

Saputro, Agil dkk. 2015. Peramalan Perencanaan Produksi Semen dengan Metode Exponential Smoothing pada PT. Semen Indonesia. Jurnal. Program Studi Teknik Industri, Fakultas Teknik, Universitas Diponegoro, Semarang

Setyawan, Eko dkk. 2016. Analisis Peramalan IForecasting) Produksi Karet (Hevea Brasiliensis) di PT Perkebunan Nusantara IX Kebun Sukamungli Kabupaten Kendal. Jurnal. Program Studi Agribisnis Fakultas Pertanian, Universirtas Wahid Hasyim, Semarang

Sidik, Nur. 2010. Forecasting Volume Produksi Tanaman Pangan, Tanaman Perkebunan Rakyat Kab. Magelang dengan Metode Exponential Smoothing Berbantu Minitab. Tugas Akhir. Jurusan Matematika, Fakultas Matematika dan Ilmu Pengetahuan Alam, Universitas Negeri Semarang, Semarang

Sugiyono. 2014. Metode Penelitan Manajemen. Jakarta: Penerbit Alfabeta

Sumayang, Lalu. 2003. Dasar - dasar Manajemen Produksi dan Operasi. Edisi Pertama. Jakarta: Salemba Empat.

Thedy, William. 2013. Peramalan Penjualan Kantong Plastik di PT. Megah Plastik dengan Menggunakan Metode ARIMA BOX JENKINS. Skripsi Departemen Teknik Industri, Fakultas Teknik, Universitas Sumatera Utara, Medan

T. Hani Handoko. 2016. Dasar-Dasar Manajemen Produksi dan Operasi. Yogyakarta. BPFE

Yusuf, Muri. 2014. Metode Penelitian Kuantitatif, Kualitatif \& Penelitian Gabungan. Jakarta. Kencana 